\title{
Should mechanical dyssynchrony be assessed in patients with implantable cardioverter- defibrillators?
}

\author{
Mark J. Boogers, $M D,{ }^{\mathrm{a}, \mathrm{b}}$ Martin J. Schalij, $M D, P h D,{ }^{\mathrm{a}}$ and Jeroen J. Bax, $M D, \mathrm{PhD}^{\mathrm{a}}$
}

See related article, pp. 398-404

Implantable cardioverter-defibrillator (ICD) therapy represents a cornerstone treatment in patients at risk for sudden cardiac death. ${ }^{1,2}$ Indications for ICD therapy have evolved considerably from survivors of sustained ventricular tachycardia or ventricular fibrillation to patients with depressed left ventricular (LV) systolic function (LV ejection fraction (LVEF) $<30-40 \%$ ), regardless of prior ventricular tachyarrhythmias. ${ }^{3-8}$

The merits of ICD therapy have been demonstrated in several large randomized trials. ${ }^{3-8}$ The first Multicenter Automatic Defibrillator Implantation Trial (MADIT) was one of the first studies evaluating the effectiveness of defibrillator therapy on the reduction of arrhythmic death in patients with depressed LV systolic function. ${ }^{7}$ The prospectively designed study evaluated whether prophylactic ICD implantation showed improved survival when compared to conventional medical therapy alone. Over a 5-year course, 196 patients with a prior myocardial infarction and depressed LV systolic function (LVEF $\leq$ $35 \%$ ) were enrolled and randomly assigned to ICD therapy $(n=95)$ or medical therapy alone $(n=101)$. During a mean follow-up of 27 months, all-cause mortality was significantly lower in patients with ICD therapy as compared to patients with conventional medication alone (16\% vs $39 \%, P<.05)$. The MADIT I trial has shown that the use of prophylactic ICD therapy was associated with a significantly improved survival as compared to patients on medical therapy (HR $0.46,95 \%$ CI $0.26-0.82$, $P<.01)$.

From the Department of Cardiology, ${ }^{\text {a }}$ Leiden University Medical Center, Leiden, The Netherlands and The Interuniversity Cardiology Institute of the Netherlands, ${ }^{\mathrm{b}}$ Utrecht, The Netherlands.

Reprint requests: Jeroen J. Bax, MD, PhD, Department of Cardiology, Leiden University Medical Center, Albinusdreef 2, 2333 ZA Leiden, The Netherlands; j.j.bax@lumc.nl.

J Nucl Cardiol 2010;17:354-8.

$1071-3581 / \$ 34.00$

Copyright (C) 2010 The Author(s). This article is published with open access at Springerlink.com

doi:10.1007/s12350-010-9222-6
Even though the efficacy of ICD therapy have been demonstrated in several landmark trials, ${ }^{3-8}$ the risk of cardiac death remained considerably high in patients who underwent ICD implantation. ${ }^{9-11}$ Several randomized trials have shown that a substantial number of ICD recipients died because of progressive heart failure. ${ }^{9-11}$ The recent randomized clinical Immediate Risk Stratification Improves Survival (IRIS) trial, which was designed to evaluate the efficacy of early ICD therapy (within 40 days of myocardial infarction) in patients with depressed LV systolic function, showed that the number of ICD recipients who died because of nonsudden cardiac death was considerably high; more than $15 \%$ of the ICD recipients died over a mean follow-up of 37 months. ${ }^{9}$ Additionally, post-hoc analysis of the Sudden Cardiac Death in Heart Failure Trial (SCDHeFT) revealed that progressive heart failure contributed significantly to all-cause mortality in patients with ICD treatment. ${ }^{11}$ Progressive heart failure was identified as the mode of death in $40 \%$ of the ICD recipients who died over a mean follow-up of 45.5 months. ${ }^{11}$

Cardiac resynchronization therapy (CRT) represents an effective treatment option in patients with moderateto-severe drug-refractory heart failure. ${ }^{12-15}$ Resynchronization therapy has been shown to improve the inherent electrical cardiac function by stimulating the ventricles in a synchronized manner. ${ }^{12-15}$ The improvement in cardiac performance, induced by synchronized pacing (which restores the intrinsic electrical conduction), has been consistently demonstrated in patients with moderate-to-severe heart failure (NYHA functional class III or IV) and ventricular conduction delay. ${ }^{12-15}$ The Comparison of Medical Therapy, Pacing and Defibrillation in Heart Failure (COMPANION) trial demonstrated that resynchronization therapy resulted in a 19\% risk reduction of the primary endpoint (time to death from or hospitalization for any cause) as compared to optimal medical therapy alone in 1520 patients with NYHA functional class III or IV heart failure (HR 0.81, $P=.014) .{ }^{14}$ Additionally, a recent post-hoc analysis of the COMPANION trial was published evaluating the effect of CRT on the number of hospitalizations during follow-up. ${ }^{15}$ In this study, resynchronization therapy was associated with a $44 \%$ reduction of heart failure 
hospital admissions and a $21 \%$ reduction of all-cause hospitalizations per patient-year of follow-up.

Recently, the hypothesis that resynchronization therapy may delay or interrupt the progressive decline in cardiac function in patients with mild heart failure, as indicated by NYHA functional class I or II, was evaluated in the Resynchronization Reverses Remodeling in Systolic Left Ventricular Dysfunction (REVERSE) trial. ${ }^{16}$ St. John Sutton et al $^{16}$ sought to determine whether patients with NYHA I-II heart failure showed favorable effects on LV geometry and function with resynchronization therapy. In total, 610 patients with mild heart failure (NYHA functional class I-II), depressed LV systolic function ( $\mathrm{LVEF} \leq 40 \%$ ), prolonged QRS interval $(\geq 120 \mathrm{~ms})$ and LV end-diastolic dimension $(\geq 55 \mathrm{~mm})$ were included. Randomization of patients was performed according to a 2:1 model; 419 patients received resynchronization therapy (on top of optimal medical treatment) and 191 patients received optimal medical therapy alone during 12 months of follow-up. Patients with CRT showed considerable reverse remodeling (as reflected by a significant decrease in LVESV and LVEDV index) as compared to patients without CRT during 12 months. Moreover, LV systolic function improved significantly in patients with resynchronization therapy $(27.2 \% \pm 6.6 \%$ vs $31.8 \% \pm 8.8 \%, P<.01)$, whereas no significant improvement was observed in patients without resynchronization therapy. Thus, favorable effects on LV structure and function were observed in patients with mild heart failure and resynchronization therapy. Moreover, the authors postulated that the progressive deterioration of cardiac function in patients with mild heart failure may be delayed or interrupted by resynchronization therapy, and probably this may lead to a change in the natural course of the disease.

Additionally, the value of resynchronization therapy in patients with mild heart failure and depressed LV systolic function was addressed by the Multicenter Automatic Defibrillator Implantation Trial with Cardiac Resynchronization Therapy (MADIT-CRT) trial. ${ }^{17} \mathrm{~A}$ total of 1820 patients with mild heart failure symptoms and depressed LV systolic function (LVEF $\leq 30 \%$ ) were included. During a mean follow-up of 2.4 years, the primary endpoint (defined as all-cause mortality or nonfatal heart failure events) was significantly less often documented in patients receiving CRT-D when compared to patients receiving ICD treatment alone $(17.2 \%$ vs $25.3 \%, P<.01)$. More specifically, a risk reduction of $34 \%$ for primary endpoint events was observed for patients receiving CRT-D (HR 0.66, 95\% CI 0.52-0.84, $P<.01$ ), as compared with those in the ICD group. These positive effects of CRT-D were primarily driven by a $41 \%$ risk reduction of the risk for nonfatal heart failure events (HR 0.59, 95\% CI 0.47-0.74, $P<.01$ ).
Despite its beneficial effects, the efficacy of resynchronization therapy has not been demonstrated in all patients currently indicated for CRT. ${ }^{18-20}$ It has been demonstrated that a substantial group of patients (30$40 \%$ ), who were selected according to current criteria on CRT, did not show significant improvement in heart failure symptoms or LV systolic performance. ${ }^{21,22} \mathrm{LV}$ dyssynchrony may play an important role as it has been identified as an important predictor of response to CRT. ${ }^{21,22}$ Multiple clinical studies have shown that preexistent LV dyssynchrony predicts response to CRT in patients with symptomatic advanced heart failure despite optimal pharmacologic treatment. ${ }^{21,23-25}$ Acute hemodynamic improvement after CRT has been related to LV dyssynchrony at baseline. ${ }^{23,25,26}$ Breithardt et $\mathrm{al}^{26}$ sought to determine whether pre-existent LV dyssynchrony predicts acute response to CRT in 34 patients with heart failure. LV dyssynchrony was evaluated using echocardiographic phase analysis of LV septal and lateral wall motion and the absolute difference in septal and lateral wall motion phase angle $(\Delta \mathrm{LS})$ was used as an indicator of LV dyssynchrony. Accordingly, patients were stratified into patients with or without LV dyssynchrony. In all patients, acute hemodynamic response to CRT was expressed in percentage increase in $\mathrm{dP} /$ dtmax. Patients with baseline LV dyssynchrony showed significantly larger increase in $\mathrm{dP} / \mathrm{dtmax}$ with $\mathrm{CRT}$ as compared to patients without LV dyssynchrony $(26 \% \pm 14 \%$ vs $2 \% \pm 1 \%, P<.05)$ at baseline. Accordingly, the study demonstrated that LV dyssynchrony could be used for identification of patients who showed acute response to CRT.

Additionally, the value of LV dyssynchrony has been demonstrated in studies evaluating the long-term effects of CRT. ${ }^{27,28}$ Sogaard et $\mathrm{al}^{27}$ evaluated whether baseline LV dyssynchrony could predict the long-term effects of CRT. Twenty-five consecutive patients with advanced heart failure and left-bundle branch block configuration were enrolled. The study demonstrated that the extent of baseline LV dyssynchrony (as assessed with 3D echocardiography and tissue Doppler imaging) was predictive for long-term response to CRT. Recently, the prospective study performed by Soliman et $\mathrm{al}^{28}$ sought to determine the role of LV dyssynchrony as assessed with 3D echocardiography for prediction of long-term response to CRT. The patient population consisted of 90 patients who were referred for CRT because of severe drug-resistant heart failure. All patients underwent echocardiographic evaluation before and 12 months after CRT. The standard deviation of time to minimum systolic volume of the $16 \mathrm{LV}$ segments was used to define the systolic dyssynchrony index (SDI). CRT response was defined as a $>15 \%$ decrease in LV end-systolic volume. A SDI $>10 \%$ 
yielded a sensitivity of $96 \%$ and a specificity of $88 \%$ for prediction of long-term response to CRT.

Thus, LV dyssynchrony may aid to identify potential responders to resynchronization therapy. Currently, the majority of studies have focused on echocardiographic techniques to evaluate the extent of LV dyssynchrony..$^{21,23-26}$ Despite its potentials, one of the major drawbacks of echocardiographic assessment of LV dyssynchrony remains its high intra- and interobserver variability; an issue that has been addressed in the Predictors of Response to Cardiac Resynchronization Therapy (PROSPECT) trial. ${ }^{29}$ As a consequence, the results of the PROSPECT trial have prompted the search for improved techniques to assess LV dyssynchrony.

Phase analysis on gated myocardial perfusion single photon emission computed tomography (SPECT) has emerged as an interesting technique that provides information on cardiac wall motion in addition to the evaluation of myocardial infarction and ischemia. ${ }^{30,31}$ Currently, several nuclear studies using phase analysis on gated myocardial perfusion SPECT have demonstrated that LV dyssynchrony provides useful information in patients with CRT. ${ }^{32,33}$ Henneman et $\mathrm{al}^{33}$ evaluated whether phase analysis on gated myocardial perfusion SPECT was able to predict response to CRT at 6 months in 42 patients with advanced heart failure. An improvement of $\geq 1$ New York Heart Association (NYHA) functional class was used as a criterion for CRT response. The extent of LV dyssynchrony was significantly larger in responders as compared to nonresponders to CRT, as reflected by higher values of histogram bandwidth $\left(175 \pm 63^{\circ}\right.$ vs $\left.117 \pm 51^{\circ}, P<.01\right)$ and phase standard deviation $\left(56.3 \pm 19.9^{\circ}\right.$ vs $\left.37 \pm 14.4^{\circ}, P<.01\right)$ in responders to CRT. Furthermore, ROC curve analysis was performed to identify the optimal point for prediction of response to CRT. A cutoff point of $135^{\circ}$ for histogram bandwidth yielded a sensitivity and specificity of $70 \%$ for prediction of response to CRT. For phase standard deviation, a cutoff point of $43^{\circ}$ yielded a sensitivity and specificity of $74 \%$ for prediction of CRT response. As a result, this study demonstrated that LV dyssynchrony derived from phase analysis on gated myocardial perfusion SPECT could be used to identify responders to CRT.

Accordingly, the question comes up whether LV dyssynchrony can also be used to identify patients with ICD therapy who will show additional benefit from receiving combined resynchronization-defibrillator therapy. Even though this was not tested in the study by Aijaroudi et al, ${ }^{34}$ the study clearly demonstrated that LV dyssynchrony was associated with increased risk of adverse cardiovascular events in ICD recipients. The retrospective study by Aijaroudi et $\mathrm{al}^{34}$ was based on 70 patients with depressed LV systolic function $($ LVEF $<$
40\%) and ICD therapy. For comparison reasons, 157 control patients with normal LV systolic function were enrolled. Stress-rest gated myocardial perfusion SPECT imaging was performed in all patients within 6 weeks prior to ICD implantation. Automated phase analysis was applied to the conventional gated SPECT data sets to evaluate the extent of baseline LV dyssynchrony, as reflected by the histogram bandwidth and phase standard deviation. Furthermore, all-cause mortality and appropriate ICD shocks (both were used as the primary endpoint) were identified in all patients during clinical follow-up. All-cause mortality or appropriate ICD shock was identified in $8(11 \%)$ patients at 1-year follow-up. ICD patients showed significantly more LV dyssynchrony as compared to the healthy control patients. In addition, phase standard deviation $\left(60^{\circ} \pm 5^{\circ}\right.$ vs $\left.50^{\circ} \pm 21^{\circ}, P<.01\right)$ was significantly higher in patients with an event as compared to patients without an event during follow-up, and the histogram bandwidth $\left(185^{\circ} \pm 37^{\circ}\right.$ vs $\left.154^{\circ} \pm 75^{\circ}, P=.07\right)$ tended to be higher in patients with an event as compared to patients without an event. Moreover, a phase standard deviation of $<50^{\circ}$ was associated with no events during follow-up. Importantly, the study suggests that patients with extensive LV dyssynchrony have an increased risk for cardiac death partially due to progressive heart failure.

Although the current study provides important information for prognostication of ICD patients, some limitations need to be considered. The association between baseline LV dyssynchrony and cardiovascular events was evaluated in a small subset of patients using a retrospective approach. A prospective analysis would have been preferred when evaluating the predictive value of LV dyssynchrony in ICD patients. Furthermore, the current findings are based on a small number of adverse events. In total, only 8 patients ( 3 patients died and 5 patients received appropriate ICD shock) showed an event at 1-year follow-up. Moreover, a combined endpoint (consisting of all-cause mortality and appropriate ICD shocks) was used to evaluate the predictive value of baseline LV dyssynchrony in ICD recipients. However, a single endpoint (cardiac death due to progressive heart failure) would have been preferred to assess the predictive value of baseline LV dyssynchrony in ICD patients.

Additional prospective studies are needed that evaluate whether LV dyssynchrony can be used to select patients who should receive combined resynchronization-defibrillator therapy or defibrillator therapy alone. These prospective studies should stratify patients, who are currently indicated for ICD therapy, according to the presence of baseline LV dyssynchrony into patients with or without LV dyssynchrony; patients with baseline LV dyssynchrony should receive combined resynchronization-defibrillator therapy, whereas patients without 
baseline LV dyssynchrony should receive defibrillator therapy alone. These prospectively designed studies will establish the actual role of LV dyssynchrony in patients currently indicated for ICD therapy.

\section{Acknowledgments}

Mark J. Boogers is supported by the Dutch Heart Foundation grant number 2006T102. Martin J. Schalij received research grants from Boston Scientific, Medtronic and Biotronik. Jeroen J. Bax received research grants from Medtronic, Boston Scientific, Biotronik, Edwards Lifesciences, BMS medical imaging, St. Jude Medical and GE Healthcare.

\section{Open Access}

This article is distributed under the terms of the Creative Commons Attribution Noncommercial License which permits any noncommercial use, distribution, and reproduction in any medium, provided the original author(s) and source are credited.

\section{References}

1. Epstein AE, DiMarco JP, Ellenbogen KA, Estes NA III, Freedman RA, Gettes LS, et al. ACC/AHA/HRS 2008 Guidelines for Device-Based Therapy of Cardiac Rhythm Abnormalities: A report of the American College of Cardiology/American Heart Association Task Force on Practice Guidelines (Writing Committee to Revise the ACC/AHA/NASPE 2002 Guideline Update for Implantation of Cardiac Pacemakers and Antiarrhythmia Devices): Developed in collaboration with the American Association for Thoracic Surgery and Society of Thoracic Surgeons. Circulation 2008;117:e350-408.

2. Goldberger JJ, Cain ME, Hohnloser SH, Kadish AH, Knight BP, Lauer MS, et al. American Heart Association/American College of Cardiology Foundation/Heart Rhythm Society scientific statement on noninvasive risk stratification techniques for identifying patients at risk for sudden cardiac death: A scientific statement from the American Heart Association Council on Clinical Cardiology Committee on Electrocardiography and Arrhythmias and Council on Epidemiology and Prevention. Circulation 2008;118: 1497-518.

3. A comparison of antiarrhythmic-drug therapy with implantable defibrillators in patients resuscitated from near-fatal ventricular arrhythmias. The Antiarrhythmics versus Implantable Defibrillators (AVID) Investigators. N Engl J Med 1997;337:1576-83.

4. Connolly SJ, Hallstrom AP, Cappato R, Schron EB, Kuck KH, Zipes DP, et al. Meta-analysis of the implantable cardioverter defibrillator secondary prevention trials. AVID, CASH and CIDS studies. Antiarrhythmics vs Implantable Defibrillator study. Cardiac Arrest Study Hamburg. Canadian Implantable Defibrillator Study. Eur Heart J 2000;21:2071-8.

5. Kuck KH, Cappato R, Siebels J, Ruppel R. Randomized comparison of antiarrhythmic drug therapy with implantable defibrillators in patients resuscitated from cardiac arrest: The Cardiac Arrest Study Hamburg (CASH). Circulation 2000;102: 748-54.
6. Connolly SJ, Gent M, Roberts RS, Dorian P, Roy D, Sheldon RS, et al. Canadian implantable defibrillator study (CIDS): A randomized trial of the implantable cardioverter defibrillator against amiodarone. Circulation 2000;101:1297-302.

7. Moss AJ, Hall WJ, Cannom DS, Daubert JP, Higgins SL, Klein H, et al. Improved survival with an implanted defibrillator in patients with coronary disease at high risk for ventricular arrhythmia. Multicenter Automatic Defibrillator Implantation Trial Investigators. N Engl J Med 1996;335:1933-40.

8. Moss AJ, Zareba W, Hall WJ, Klein H, Wilber DJ, Cannom DS, et al. Prophylactic implantation of a defibrillator in patients with myocardial infarction and reduced ejection fraction. N Engl J Med 2002;346:877-83

9. Steinbeck G, Andresen D, Seidl K, Brachmann J, Hoffmann E, Wojciechowski D, et al. Defibrillator implantation early after myocardial infarction. N Engl J Med 2009;361:1427-36.

10. Hohnloser SH, Kuck KH, Dorian P, Roberts RS, Hampton JR, Hatala R, et al. Prophylactic use of an implantable cardioverterdefibrillator after acute myocardial infarction. N Engl J Med 2004;351:2481-8

11. Packer DL, Prutkin JM, Hellkamp AS, Mitchell LB, Bernstein RC, Wood F, et al. Impact of implantable cardioverter-defibrillator, amiodarone, and placebo on the mode of death in stable patients with heart failure. Analysis from the Sudden Cardiac Death in Heart Failure Trial. Circulation 2009;120:2170-6.

12. Hunt SA, Abraham WT, Chin MH, Feldman AM, Francis GS, Ganiats TG, et al. 2009 focused update incorporated into the ACC/ AHA 2005 Guidelines for the Diagnosis and Management of Heart Failure in Adults: A report of the American College of Cardiology Foundation/American Heart Association Task Force on Practice Guidelines: Developed in collaboration with the International Society for Heart and Lung Transplantation. Circulation 2009;119:e391-479.

13. Cleland JG, Daubert JC, Erdmann E, Freemantle N, Gras D, Kappenberger L, et al. The effect of cardiac resynchronization on morbidity and mortality in heart failure. N Engl J Med 2005; 352:1539-49.

14. Bristow MR, Saxon LA, Boehmer J, Krueger S, Kass DA, De MT, et al. Cardiac-resynchronization therapy with or without an implantable defibrillator in advanced chronic heart failure. N Engl J Med 2004;350:2140-50.

15. Anand IS, Carson P, Galle E, Song R, Boehmer J, Ghali JK, et al. Cardiac resynchronization therapy reduces the risk of hospitalizations in patients with advanced heart failure: Results from the Comparison of Medical Therapy, Pacing and Defibrillation in Heart Failure (COMPANION) trial. Circulation 2009;119:969-77.

16. St. John Sutton M, Ghio S, Plappert T, Tavazzi L, Scelsi L, Daubert $\mathrm{C}$, et al. Cardiac resynchronization induces major structural and functional reverse remodeling in patients with New York Heart Association class I/II heart failure. Circulation 2009;120: 1858-65.

17. Moss AJ, Hall WJ, Cannom DS, Klein H, Brown MW, Daubert JP, et al. Cardiac-resynchronization therapy for the prevention of heart-failure events. N Engl J Med 2009;361:1329-38.

18. Naccarelli GV, Luck JC, Wolbrette DL, Pae WE, Weller-Moore R, Dell'Orfano JT, et al. Pacing therapy for congestive heart failure: Is it ready for prime time? Curr Opin Cardiol 1999;14:1-3.

19. Bader H, Garrigue S, Lafitte S, Reuter S, Jais P, Haissaguerre M, et al. Intra-left ventricular electromechanical asynchrony. A new independent predictor of severe cardiac events in heart failure patients. J Am Coll Cardiol 2004;43:248-56.

20. Abraham WT, Fisher WG, Smith AL, Delurgio DB, Leon AR, Loh $\mathrm{E}$, et al. Cardiac resynchronization in chronic heart failure. N Engl J Med 2002;346:1845-53. 
21. Bax JJ, Bleeker GB, Marwick TH, Molhoek SG, Boersma E, Steendijk P, et al. Left ventricular dyssynchrony predicts response and prognosis after cardiac resynchronization therapy. J Am Coll Cardiol 2004;44:1834-40.

22. Bax JJ, Abraham T, Barold SS, Breithardt OA, Fung JW, Garrigue $\mathrm{S}$, et al. Cardiac resynchronization therapy: Part 1-Issues before device implantation. J Am Coll Cardiol 2005;46:2153-67.

23. Bax JJ, Marwick TH, Molhoek SG, Bleeker GB, van Erven L, Boersma E, et al. Left ventricular dyssynchrony predicts benefit of cardiac resynchronization therapy in patients with end-stage heart failure before pacemaker implantation. Am J Cardiol 2003;92: 1238-40.

24. Yu CM, Fung JW, Zhang Q, Chan CK, Chan YS, Lin H, et al. Tissue Doppler imaging is superior to strain rate imaging and postsystolic shortening on the prediction of reverse remodeling in both ischemic and nonischemic heart failure after cardiac resynchronization therapy. Circulation 2004;110:66-73.

25. van Dijk J, Knaapen P, Russel IK, Hendriks T, Allaart CP, de Cock CC, et al. Mechanical dyssynchrony by 3D echo correlates with acute haemodynamic response to biventricular pacing in heart failure patients. Europace 2008;10:63-8.

26. Breithardt OA, Stellbrink C, Kramer AP, Sinha AM, Franke A, Salo R, et al. Echocardiographic quantification of left ventricular asynchrony predicts an acute hemodynamic benefit of cardiac resynchronization therapy. J Am Coll Cardiol 2002;40:536-45.

27. Sogaard P, Egeblad H, Kim WY, Jensen HK, Pedersen AK, Kristensen BO, et al. Tissue Doppler imaging predicts improved systolic performance and reversed left ventricular remodeling during long-term cardiac resynchronization therapy. J Am Coll Cardiol 2002;40:723-30.

28. Soliman OI, Geleijnse ML, Theuns DA, van Dalen BM, Vletter WB, Jordaens LJ, et al. Usefulness of left ventricular systolic dyssynchrony by real-time three-dimensional echocardiography to predict long-term response to cardiac resynchronization therapy. Am J Cardiol 2009;103:1586-91.

29. Chung ES, Leon AR, Tavazzi L, Sun JP, Nihoyannopoulos P, Merlino J, et al. Results of the Predictors of Response to CRT (PROSPECT) trial. Circulation 2008;117:2608-16.

30. Chen J, Garcia EV, Folks RD, Cooke CD, Faber TL, Tauxe EL, et al. Onset of left ventricular mechanical contraction as determined by phase analysis of ECG-gated myocardial perfusion SPECT imaging: Development of a diagnostic tool for assessment of cardiac mechanical dyssynchrony. J Nucl Cardiol 2005;12:68795.

31. Chen J, Henneman MM, Trimble MA, Bax JJ, Borges-Neto S, Iskandrian AE, et al. Assessment of left ventricular mechanical dyssynchrony by phase analysis of ECG-gated SPECT myocardial perfusion imaging. J Nucl Cardiol 2008;15:127-36.

32. Henneman MM, Chen J, Ypenburg C, Dibbets-Schneider P, Bleeker GB, Boersma E, et al. Phase analysis of gated myocardial perfusion single-photon emission computed tomography compared with tissue Doppler imaging for the assessment of left ventricular dyssynchrony. J Am Coll Cardiol 2007;49:1708-14.

33. Henneman MM, Chen J, Dibbets-Schneider P, Stokkel MP, Bleeker GB, Ypenburg C, et al. Can LV dyssynchrony as assessed with phase analysis on gated myocardial perfusion SPECT predict response to CRT? J Nucl Med 2007;48:1104-11.

34. Aijaroudi WA, Hage FG, Hermann D, Doppalapudi H, Venkataraman R, Heo J, et al. Relation of left ventricular dyssynchrony by phase analysis of gated SPECT images and cardiovascular events in patients with implantable cardiac defibrillators. J Nucl Cardiol 2010, in press. 